\title{
Utilização do resíduo do beneficiamento do caulim para a produção de corpos mulíticos
}

\section{(Use of kaolin processing waste for the production of mullite bodies)}

\author{
R. R. Menezes, M. F. Oliveira, L. N. L. Santana, G. A. Neves, H. C. Ferreira \\ Departamento de Engenharia de Materiais, Universidade Federal de Campina Grande \\ Av. Aprígio Veloso 882, Bodocongó, Campina Grande, PB 58109-970 \\ romualdomenezes@dema.ufcg.edu.br,gelmires@dema.ufcg.edu.br
}

\begin{abstract}
Resumo
Nos últimos anos a indústria da extração e beneficiamento mineral vem sendo mencionada como fonte de agressão ambiental e poluição devido a grande quantidade de resíduos gerados. A indústria do beneficiamento do caulim reflete esse quadro, gerando elevada quantidade de resíduo por ano. Assim, este trabalho tem por objetivo analisar a viabilidade de utilização do resíduo do beneficiamento do caulim para a produção de corpos mulíticos. Formulações contendo resíduo de caulim e de alumina foram desenvolvidas e homogeneizadas por mistura via úmida em moinho de bolas. Em seguida confeccionaram-se corpos de prova por prensagem uniaxial, que foram submetidos a sinterização em diferentes temperaturas. Após queima os materiais foram caracterizados por difração de raios X e determinação da absorção de água, densidade aparente, retração de queima e módulo de ruptura à flexão. Os resultados evidenciaram que a temperatura de queima mais adequada varia de acordo com a composição e o teor de resíduo presente nas formulações, que temperaturas de queima muito elevadas podem conduzir o material a superqueima e que formulações contendo teores de resíduos superiores a $40 \%$ podem ser utilizadas para a produção de corpos mulíticos com elevada resistência mecânica, da ordem de $75 \mathrm{MPa}$.
\end{abstract}

Palavras-chave: resíduo, reciclagem, caulim, mulita, matérias-primas alternativas.

\begin{abstract}
In the last few years, mineral extraction and processing industries have been mentioned as sources of environmental contamination and pollution. The kaolin processing industry around the world generates large amounts of wastes. This work evaluated the kaolin processing waste suitability as alternative ceramic raw material for the production of mullite bodies. Several formulations composed of kaolin waste and alumina were prepared and homogenized in a ball mill. Test specimens were obtained by uniaxial pressing and sintering at different temperatures. Fired samples were microstructurally analyzed by X-ray diffraction. Sintered samples were characterized to determine their water absorption, apparent density, firing shrinkage and modulus of rupture. The results indicated that the amount of waste in the composition dictates the firing temperature, and that extremely high firing temperatures may lead to overfiring. Mullite formulations with more than 40\% of kaolin waste could be used for the production of bodies with high strength, of about 75MPa.
\end{abstract}

Keywords: wastes, recycling, kaolin, mullite, alternative raw materials.

\section{INTRODUÇÃO}

O grande desenvolvimento tecnológico do último século fez com que a produção de bens industrializados e o volume de recursos minerais explorados atingissem quantidade jamais vistas pela humanidade. Associado a essa grande expansão produtiva ocorreu a geração de uma enorme quantidade de resíduos urbanos e industriais, o que se tornou um dos maiores problemas para a sustentabilidade do desenvolvimento humano.

Os resíduos industriais produzidos são lançados em aterros sanitários, mas também, quando não há a adequada fiscalização por parte do estado, em terrenos baldios, córregos, ravinas, mangues, etc. $\mathrm{O}$ que se constitui uma grave fonte de contaminação e poluição, provocando impactos ambientais irreversíveis.

Dentre o grande universo de fontes poluidoras e geradoras de resíduos existentes atualmente, as indústrias de processamento e beneficiamento mineral se destacam pela quantidade de resíduos produzidos, que caminha paralelamente ao volume de produção. O que é de extrema preocupação para ambientalistas e pesquisadores, em virtude do aumento crescente da produção mineral nos últimos anos em todo mundo.

A reciclagem e a re-utilização dos resíduos minerais são excelentes alternativas deposição em aterros e ao seu descarte indiscriminado dos resíduos, reduzindo custos dos geradores desses materiais e/ou minimizando os impactos ambientais do seu inadequado tratamento e manipulação [1]. 
A reciclagem também tem grande importância econômica no segmento econômico que incorpora o resíduo, podendo está associada à economia de matérias-primas não renováveis e energia, diversificação de matérias-primas e/ou redução de custos de produção.

A incorporação dos resíduos da extração e beneficiamento mineral, em formulações cerâmicas vem se mostrado uma ótima alternativa para a economia de recursos naturais e diversificação de matérias-primas [1-8]. A indústria cerâmica tradicional é a que mais se destaca na absorção desses resíduos, em virtude, principalmente, do seu elevado volume de produção. $\mathrm{O}$ que, associado a diversidade das características físicas e químicas de suas matérias-primas, possibilita incorporar grandes quantidades dos mais diversos tipos de resíduos minerais, sem alterações significativas dos parâmetros de processamento.

A indústria da mineração e beneficiamento do caulim gera milhares de toneladas de resíduos sólidos por ano, que, em geral, são descartados indiscriminadamente no meio ambiente. O que faz com que o caulim, apesar da sua grande importância em várias indústrias, como a da borracha, do plástico, de tintas, papel, etc., esteja associado a um grande passivo ambiental.

O processamento do caulim primário produz dois tipos de resíduos. O primeiro na mineração, oriundo da etapa de separação do minério da areia grossa, representando até cerca de $70 \%$ do total produzido. O segundo é gerado na etapa de beneficiamento por via úmido, originando um resíduo fino na forma de lama [9].

Pesquisas [9-11] vêm sendo dedicadas à reciclagem do resíduo do beneficiamento do caulim através de sua incorporação em formulações cerâmicas para a produção de blocos, telhas e revestimentos cerâmicos. Entretanto, a reciclagem e a re-utilização de resíduos deve ser encarada não apenas do ponto de vista ambiental, mas também em termos de viabilidade econômica. $\mathrm{O}$ que faz com que a necessidade de se incorporar um maior valor agregado nos produtos obtidos com a utilização do resíduo de caulim ganhe evidência e importância, a fim de incentivar a absorção do resíduo no meio produtivo e favorecer a cultura do reaproveitamento e re-utilização [11].

Nesse sentido alguns trabalhos [2, 12-14] já vêm buscando agregar valor a resíduos industriais através de sua incorporação em formulações cerâmicas para a produção de refratários, porcelanas e corpos mulíticos. Corpos mulíticos encontram largo leque de aplicações em cerâmicas convencionais (porcelanas, louças, refratários, etc.) e avançadas, ocupando uma posição de destaque na indústria cerâmica em virtude das excelentes propriedades que a mulita apresenta.

A mulita é a única fase cristalina termodinamicamente estável do sistema $\mathrm{Al}_{2} \mathrm{O}_{3}-\mathrm{SiO}_{2}$, possuindo ponto de fusão por volta de $1800{ }^{\circ} \mathrm{C}$, baixa densidade, pequeno coeficiente de expansão térmica, elevada resistência mecânica e ao choque térmico e várias outras propriedades que a tornam um dos principais materiais cerâmicos. Essas propriedades fazem com que os materiais mulíticos tenham comportamento mecânico muito superior ao dos materiais cerâmicosutilizados na construção civil, como blocos, telhas e revestimentos, e agregam elevado valor aos produtos mulíticos $[15,16]$. Assim, este trabalho tem por objetivo analisar a viabilidade de utilização do resíduo do beneficiamento do caulim para a produção de corpos mulíticos.

\section{MATERIAIS E MÉTODOS}

\section{Materiais}

Nessa pesquisa foram utilizados os seguintes materiais: resíduo do processamento do caulim, proveniente da etapa de beneficiamento por via úmida (cedido pela empresa Caulisa Indústria S/A, Juazeirinho, PB) e alumina A1000SG (cedida pela empresa Alcoa Industrial, Chem. Div., EUA). A alumina apresenta um $\mathrm{D}_{50}$ de $0,6 \mu \mathrm{m}$ e um $\mathrm{D}_{90}$ de $1,9 \mu \mathrm{m}$ (dados fornecidos pelo fabricante). $\mathrm{O}$ resíduo do beneficiamento do caulim foi caracterizado em trabalhos anteriores [10, 17],

Tabela I - Composição química do resíduo de caulim.

[Table I - Chemical composition of the kaolin waste.]

\begin{tabular}{cccccccccc}
\hline Matérias-Primas & P.F. $^{\mathrm{a}}$ & $\mathrm{SiO}_{2}$ & $\mathrm{Al}_{2} \mathrm{O}_{3}$ & $\mathrm{Fe}_{2} \mathrm{O}_{3}$ & $\mathrm{~K}_{2} \mathrm{O}$ & $\mathrm{TiO}_{2}$ & $\mathrm{CaO}$ & $\mathrm{MgO}$ & $\mathrm{Na}_{2} \mathrm{O}$ \\
\hline resíduo de caulim & 6,75 & 52,68 & 33,57 & 0,93 & 5,72 & 0,12 & - & - & 0,08 \\
\hline alumina $^{\mathrm{b}}$ & - & 0,03 & 99,80 & 0,02 & - & - & 0,02 & 0,03 & 0,06 \\
\hline
\end{tabular}

$V^{a}$ perda ao fogo; ${ }^{b}$ composição segundo o fabricante.

Tabela II - Formulações com resíduo de caulim e alumina. [Table II - Formulations with kaolin waste and alumina.]

\begin{tabular}{lccccc}
\hline & \multicolumn{5}{c}{ Formulações (proporções em \%massa) } \\
\cline { 2 - 6 } Matérias-Primas & A46 & A50 & A54 & A58 & A62 \\
Resíduo de Caulim & 54 & 50 & 46 & 42 & 38 \\
Alumina & 46 & 50 & 54 & 58 & 62 \\
\hline
\end{tabular}

${ }^{a}$ composição estequiométrica com relação a composição da mulita $3 \mathrm{Al}_{2} \mathrm{O}_{3} .2 \mathrm{SiO}_{2}$ 
sendo observado que o resíduo é composto por caulinita, mica e quartzo e que, após moagem, apresenta larga distribuição do tamanho de partículas, com $\mathrm{D}_{50}$ de $53 \mu \mathrm{m}, \mathrm{D}_{10}$ de $5 \mu \mathrm{m}$ e $\mathrm{D}_{90}$ de $135 \mu \mathrm{m}$. A Tabela I apresenta a composição química do resíduo de caulim determinada por fluorescência de raios X (Shimadzu EDX-90) e da alumina (fornecida pelo fabricante).

\section{Metodologia}

O resíduo foi seco a $110{ }^{\circ} \mathrm{C}$, moído/desaglomerado em moinho de galga e peneirado através de peneira com abertura de $350 \mu \mathrm{m}$ (ABNT № 42). Foram preparadas formulações através de mistura por via úmida em moinho de bolas do
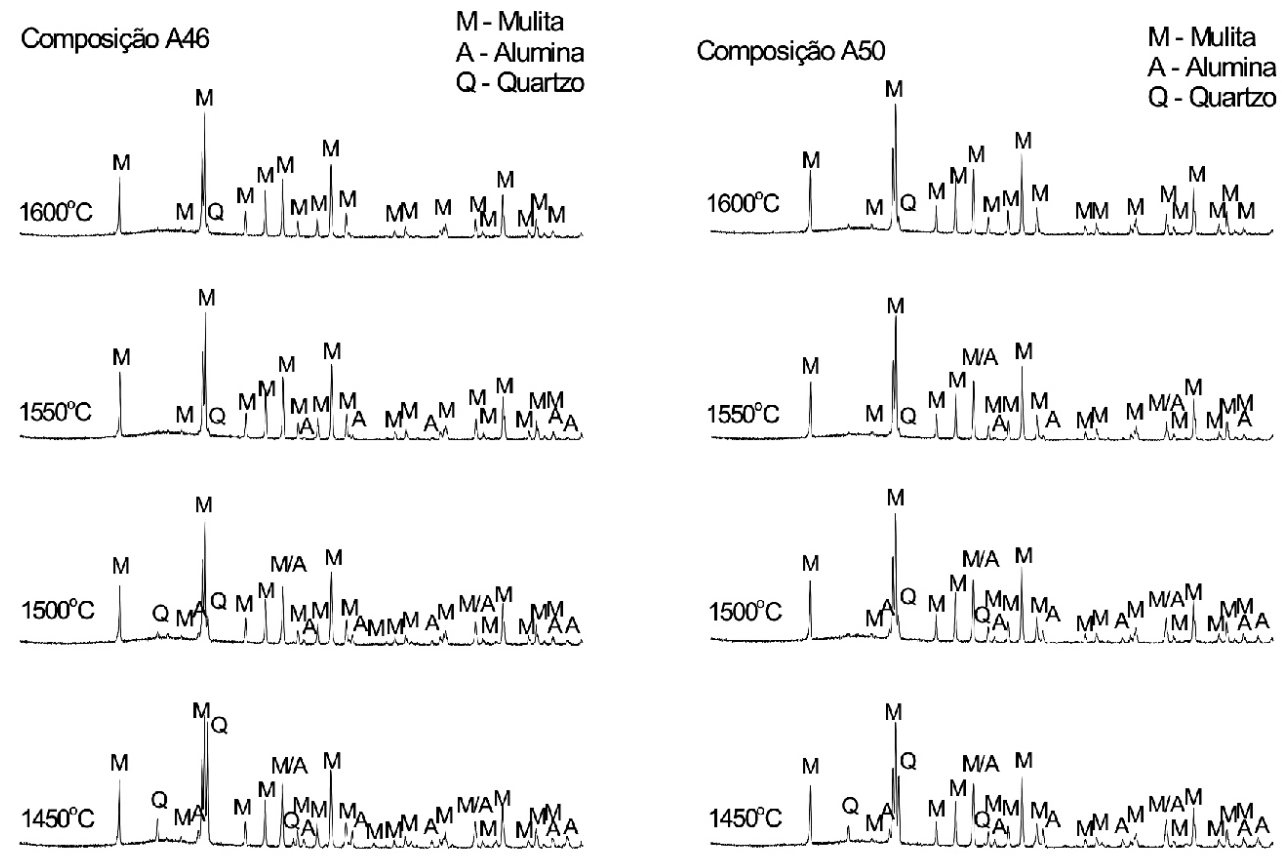

$\begin{array}{lllllllllllllllllllllllll}5 & 10 & 15 & 20 & 25 & 30 & 35 & 40 & 45 & 50 & 55 & 60 & 65 & 70\end{array}$ $2 \theta$ (grau)

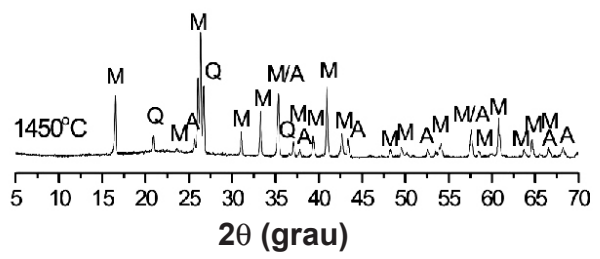

Composição A54

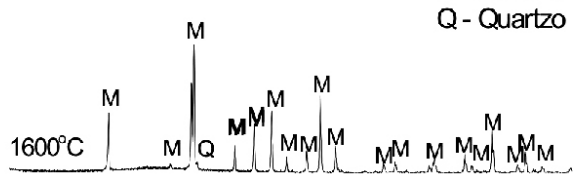

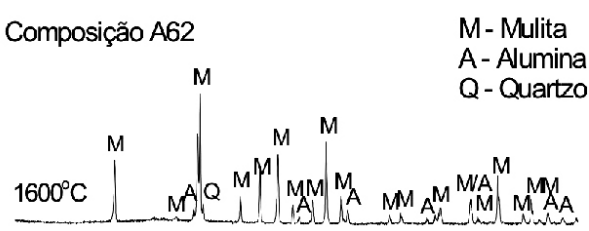
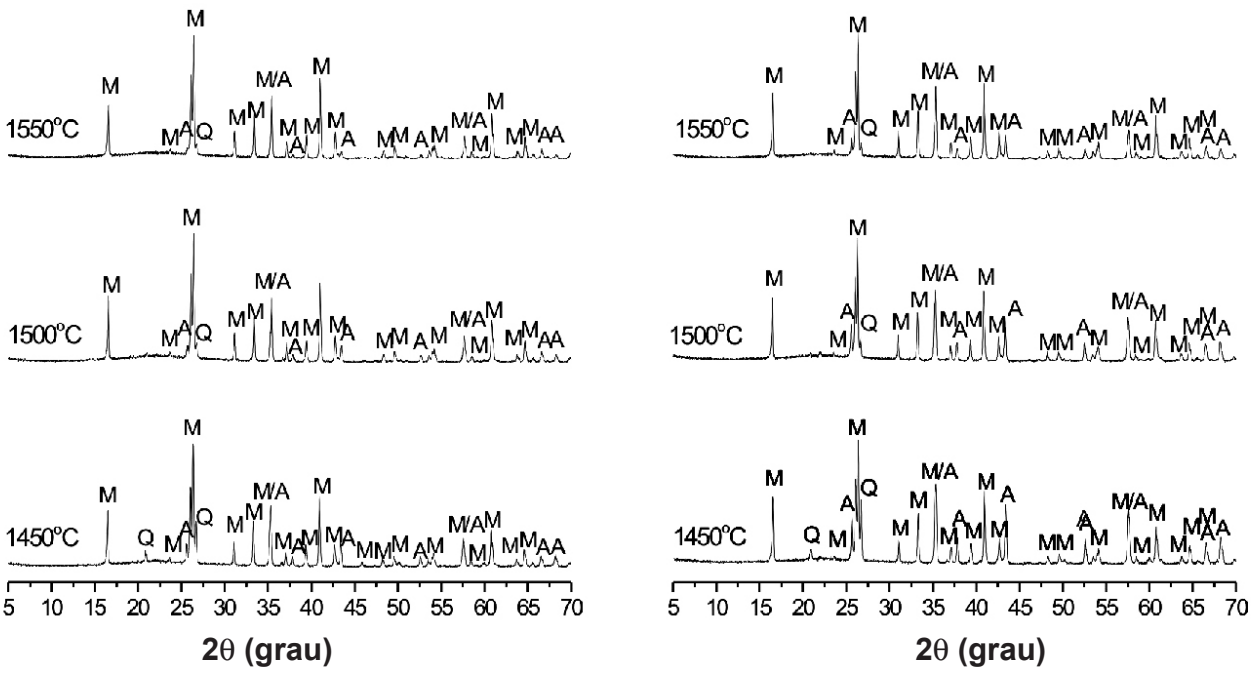

Figura 1: Padrão de difração de raios X de composições estudadas. [Figure 1: X-ray diffraction patterns of the studied formulations.] 
resíduo e da alumina, usando álcool etílico [18] como meio de dispersão. A Tabela II apresenta as composições estudadas. A composição A54 foi formulada com base na estequiométrica da mulita, $3 \mathrm{Al}_{2} \mathrm{O}_{3} \cdot 2 \mathrm{SiO}_{2}$. As composições A46 e A50 foram formuladas com excesso de sílica em relação a composição A54, enquanto que as composições A58 e A62 foram formuladas com excesso de alumina em relação a composição A54. Após mistura em moinho de bolas, as formulações foram novamente passadas em peneira com abertura de $350 \mu \mathrm{m}$ (ABNT № 42). Em seguida foram confeccionados corpos de prova de $50 \mathrm{~mm}$ x $10 \mathrm{~mm}$ x $5 \mathrm{~mm}$ por prensagem uniaxial a $30 \mathrm{MPa}$.

Os corpos de prova foram submetidos a sinterização com taxa de aquecimento de $5{ }^{\circ} \mathrm{C} /$ min e patamar de $2 \mathrm{~h}$ nas temperaturas de $1450,1500,1550$ e $1600{ }^{\circ} \mathrm{C}$. Após a sinterização foi feita a caracterização microestrutural dos corpos de prova através de difração de raios X, visando a determinação das fases cristalinas nas amostras. Os corpos de prova foram submetidos a ensaios de caracterização física. Foram determinadas a absorção de água, porosidade e densidade aparente pelo método de Arquimedes, por imersão em água. $\mathrm{O}$ módulo de ruptura à flexão foi determinado através de ensaio de flexão em três pontos (Karl Schroder D-6940 Weinheim) com velocidade de aplicação de carga de $0,5 \mathrm{~mm} / \mathrm{min}$.

\section{RESULTADOS E DISCUSSÃO}

Na Fig. 1 estão apresentados os difratogramas das composições A46, A50, A54 e A62 após queima. Observa-se nas composições A46 e A50 (composições com excesso de sílica em relação a estequiometria da mulita $3 \mathrm{Al}_{2} \mathrm{O}_{3} \cdot 2 \mathrm{SiO}_{2}$ ) as fases cristalinas alumina, mulita e quartzo após queima a 1450,1500 e $1550{ }^{\circ} \mathrm{C}$. Após queima a $1600{ }^{\circ} \mathrm{C}$, verificase que essas composições apresentaram apenas mulita e quartzo como fases cristalinas.

Uma evolução microestrutural semelhante foi observada na composição A54, observando-se após queima à 1450 ${ }^{\circ} \mathrm{C}$ alumina, quartzo e mulita como fases cristalinas e uma diminuição na quantidade de alumina e quartzo com o aumento da temperatura de queima (através da redução dos picos no padrão de difração), por conseqüência da formação de mulita. Após queima a $1600{ }^{\circ} \mathrm{C}$, constatou-se a presença de mulita e quartzo como fases cristalinas. Não se esperava obter na composição A54, quartzo residual após queima a $1600^{\circ} \mathrm{C}$, entretanto, a pequena quantidade (pico com pequena intensidade no padrão de difração) observada poderia está associada a uma pequena deficiência na quantidade de alumina utilizada.

A caulinita $\left(\mathrm{Al}_{2} \mathrm{O}_{3} \cdot 2 \mathrm{SiO}_{2} \cdot 2 \mathrm{H}_{2} \mathrm{O}\right)$ apresenta em sua composição 46,5\% de sílica, no entanto, através da Tabela I, observa-se que há cerca de $52,7 \%$ de sílica no resíduo. Esse excesso de sílica é oriundo da mica e do quartzo presentes no resíduo $[10,15]$. Quando há uma quantidade de quartzo muito grande na formulação, de modo que sua dissolução, durante a queima, satura a fase líquida presente, ocorre a cristalização de cristobalita na interface quartzo-líquido
[19]. O que sugere que o quartzo observado após a queima a $1600{ }^{\circ} \mathrm{C}$ não está associado a processos de dissolução, saturação e cristalização, já que nesse caso observar-se-ia a presença de cristobalita. A não presença de cristobalita nos difratogramas também sugere que a dissolução do quartzo presente no resíduo possui uma baixa cinética, chegando a não saturar a fase líquida presente, o que está provavelmente associado ao elevado tamanho das partículas de quartzo.

Deve-se comentar que apesar de se está trabalhando com um material rico em caulinita e quartzo, como o resíduo, e com alumina, as composições, principalmente aquelas ricas em sílica (com maior quantidade de resíduo), devem apresentar durante a queima a formação de uma grande quantidade de fase líquida, devido ao elevado teor de óxidos fundentes presentes no resíduo, superior a $6 \%$, como pode ser observado na Tabela I. Como conseqüência, durante a queima as composições podem apresentar comportamento semelhante ao de materiais com elevada quantidade de fase vítrea (líquida na queima), como as formulações triaxiais. A presença de grande quantidade de fase vítrea favorecerá o desenvolvimento não apenas de
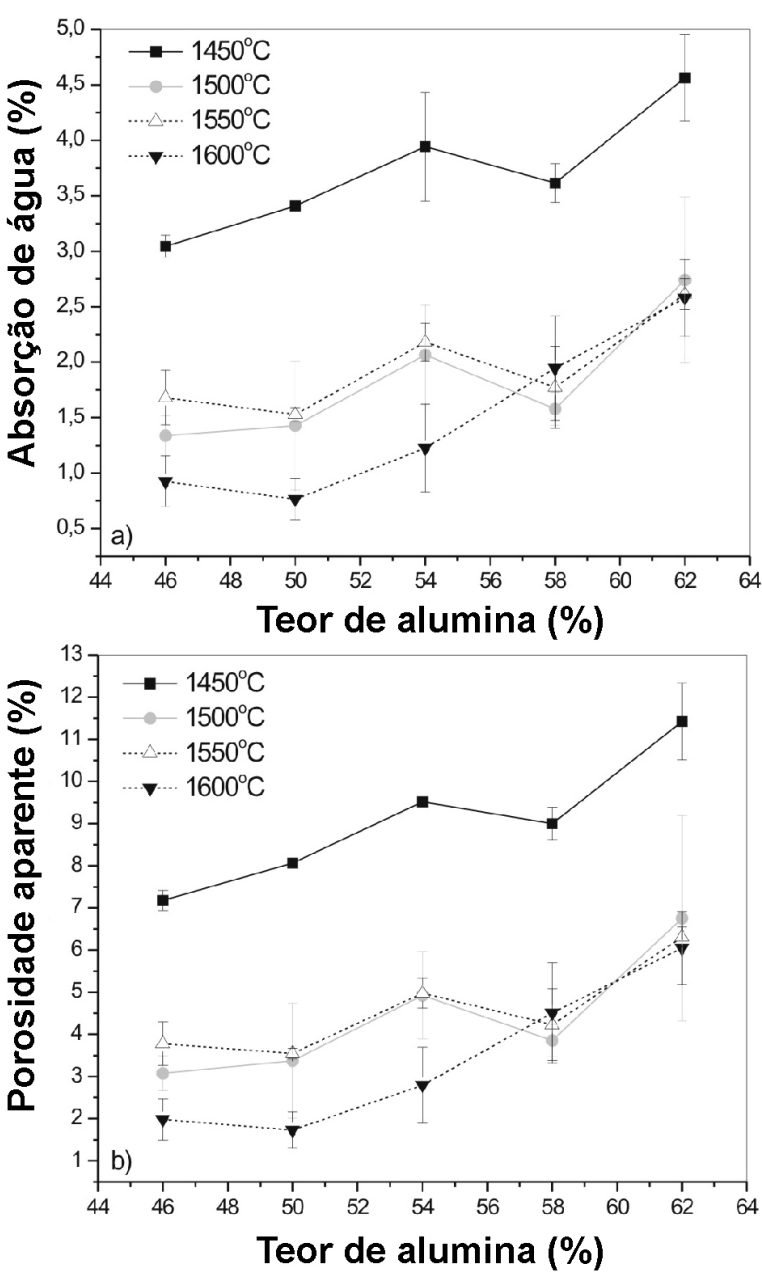

Figura 2: Absorção de água (a), e porosidade aparente (b), dos corpos de prova após queima.

[Figure 2: Water absorption (a) and apparent porosity (b) of the fired sample bodies.] 


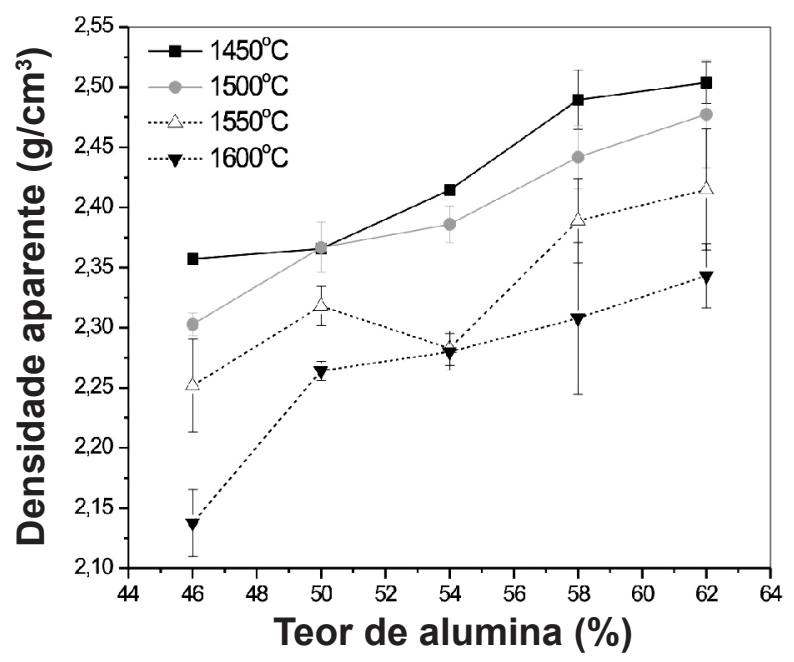

Figura 3: Densidade aparente dos corpos de prova após queima. [Figure 3: Apparent density of the fired sample bodies.]

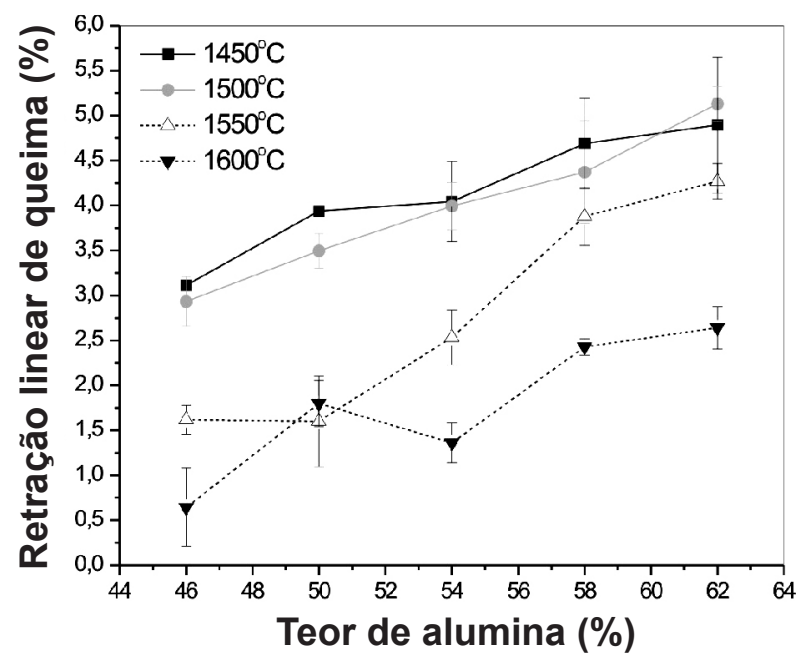

Figura 4: Retração linear de queima dos corpos de prova.

[Figure 4: Linear firing shrinkage of the sample bodies.]

mulita primária, mas também de grande quantidade de mulita secundária e possivelmente terciária [18].

As composições A58 e A62 (com excesso de alumina em relação a estequiometria da mulita $3 \mathrm{Al}_{2} \mathrm{O}_{3} \cdot 2 \mathrm{SiO}_{2}$ ), apresentaram evoluções microestruturais semelhantes com o aumento da temperatura de queima (na Fig. 1 só está presente o difratograma da composição A62, em virtude da composição A58 apresentar difratogramas semelhantes ao da composição A62). Após queima a $1450{ }^{\circ} \mathrm{C}$ observou-se a presença de alumina, quartzo e mulita como fases cristalinas. Com o aumento da temperatura de queima observou-se uma redução gradual na quantidade de quartzo (pela redução na intensidade do pico principal), entretanto, após queima a $1600{ }^{\circ} \mathrm{C}$, verificou-se a presença, nessas composições, de mulita, quartzo e alumina, apesar do excesso de alumina utilizado. O que leva a concluir que o quartzo residual observado na composição A54 após queima a $1600{ }^{\circ} \mathrm{C}$, não estava associado a uma pequena deficiência na quantidade de alumina.

Deve-se ressaltar que em virtude da formação de uma grande quantidade de fase vítrea nas composições estudas, e do elevado teor de alumina nas composições A58 e A62, a mulita observada na Fig. 1 provavelmente representa uma mistura de mulita primária, secundária e terciária $[18,20]$.

Com base em trabalhos da literatura $[17,21]$ que abordaram produção de corpos mulíticos, verifica-se que quando se utiliza quartzo grosseiro ou este está presente como acessório nas matérias-primas (tamanho médio maior que $20 \mu \mathrm{m}$ ) é possível a presença de quartzo como fase residual, mesmo após altas temperaturas de queima [19, 21]. A reação de formação de mulita apresenta uma cinética muito baixa em temperaturas inferiores a temperatura de eutético do sistema sílica-alumina, $1587{ }^{\circ} \mathrm{C}$ [22], o que ressalta a necessidade da utilização de matérias-primas com granulometria fina para uma total mulitização no sistema estudado. Em pesquisas [23-25] também se observou que a utilização de materiais com granulometria fina (tamanho médio menor que $5 \mu \mathrm{m}$ ) possibilita eliminar o quartzo nas matérias-primas, mesmo em elevadas quantidades, após queima em temperaturas da ordem de $1400{ }^{\circ} \mathrm{C}$, obtendose corpos contendo apenas mulita como fase cristalina ou compósitos alumina-mulita.

O resíduo estudado possui uma granulometria grosseira, com partículas da ordem de $130 \mu \mathrm{m}$, o que pode ser a causa da presença de quartzo nas composições A54, A58 e A62 mesmo após queima a $1600{ }^{\circ} \mathrm{C}$. A maior proporção de alumina nas formulações reduz a quantidade de fase líquida formada, reduzindo a capacidade de dissolução do quartzo, o que associado ao elevado tamanho das partículas de quartzo (e, por conseguinte, menor cinética de dissolução e de reação) poderia explicar a presença dessa fase cristalina após a queima a $1600{ }^{\circ} \mathrm{C}$.

A Fig. 2 apresenta a absorção de água e a porosidade aparente das composições estudadas. Pode-se observar, que de forma geral, tanto a absorção e a porosidade aparente aumentam com a quantidade de alumina, sendo esse comportamento observado em todas as temperaturas de queima utilizadas no estudo. Verifica-se também, que a absorção e a porosidade diminuíram com a elevação da temperatura de queima atingindo valores inferiores a $1 \% \mathrm{e}$ $2 \%$ respectivamente, após a queima a $1600^{\circ} \mathrm{C}$.

As Figs. 3 e 4 apresentam a densidade aparente e a retração linear de queima das composições estudadas respectivamente. Observa-se que a densidade e a retração apresentaram comportamentos semelhantes frente a quantidade de alumina utilizada nas formulações, ambos os parâmetros aumentaram com a elevação no teor de alumina nas composições. A densidade e a retração também apresentaram comportamento semelhante com relação ao aumento da temperatura de queima, observando-se, de forma geral, uma diminuição de ambas com a elevação da temperatura de queima.

Como não foram observadas variações microestruturais e nem se espera alterações composicionais significativas nas formulações estudadas durante a queima, o comportamento 


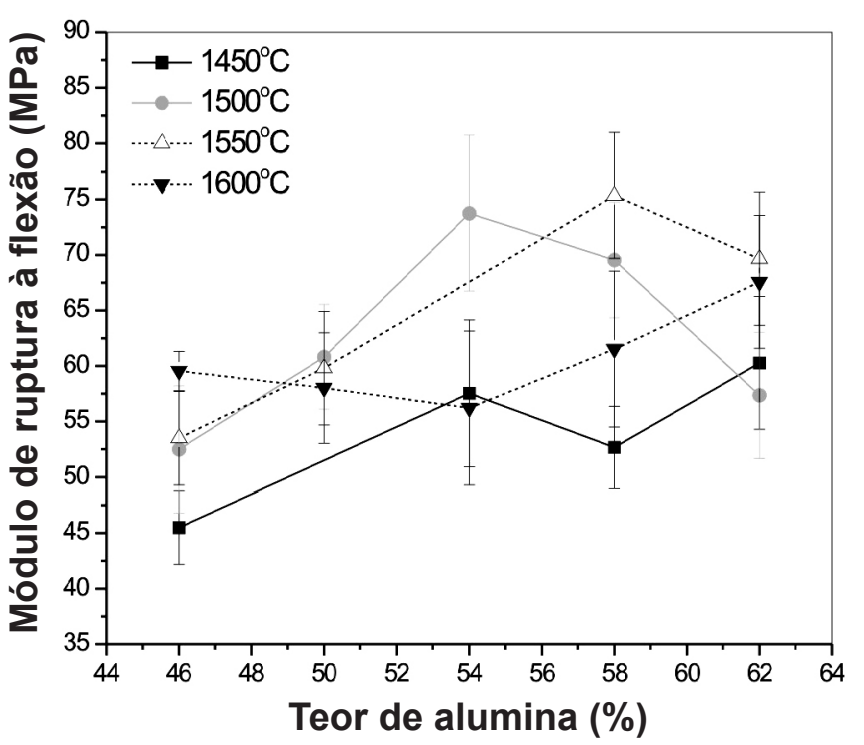

Figura 5: Módulo de ruptura dos corpos de prova após queima. [Figure 5: Modulus of rupture of the fired samples.]

observado nas Figs. 3 e 4, de decréscimo da densidade aparente e da retração de queima com o aumento da temperatura de sinterização, pode ser o resultado do aumento no número e tamanho dos poros no material devido à "superqueima" (do inglês "overfiring") e "inchamento" ("bloating"). A porosidade dos materiais que sofreram "superqueima" pode ter várias fontes. No presente estudo, a causa mais provável é a expansão dos gases aprisionados nos estágios iniciais da queima. Estes gases são continuamente liberados durante a queima, podendo ser originários da decomposição das matérias-primas, da queima de compostos orgânicos, de reações de redução em elevadas temperaturas, etc.. No entanto, quando ocorre a vitrificação, e quantidade substancial de fase líquida se forma, esses gases têm que difundir através da fase líquida, ocorrendo o aprisionamento desses gases, sob elevadas pressões, dentro do corpo e, por conseguinte, a formação de poros (bolhas) no seu interior. Deve-se salientar que esse aprisionamento de gases está associado à viscosidade da fase líquida; quanto mais viscosa, maior a dificuldade de difusão dos gases, e maior o aprisionamento dos gases no corpo cerâmico. Esses gases quando atingem a superfície da peça podem escapar, formando poros abertos ou inchamentos na superfície do material $[19,26,27]$.

$\mathrm{O}$ fato da densidade aparente decrescer enquanto que a absorção de água altera-se pouco (ou fica constante), situando-se próximo ao mínimo atingido (com o aumento da temperatura de queima) sugere que a porosidade formada é fechada, enquanto que a porosidade interconectada que se forma quando o gás escapa na superfície é rapidamente penetrada por líquido [27]. Quando aprisionados no interior do material, os gases por um processo de difusão à semelhança do "Ostwald ripening" observado em crescimento de grão, sob a força motriz da elevada pressão nos poros menores, migram para poros maiores, ocorrendo diminuição da densidade de poros pequenos e formação de grandes poros [27], que irão comprometer a densificação do material, a retração de queima associada à densificação e a resistência mecânica do material de forma mais acentuada.

O resíduo apresenta um baixo teor de ferro, inferior a 1\%, o que faz com que os autores acreditem que a maior quantidade de gases formados, e aprisionados, durante a queima esteja associado à decomposição dos constituintes presentes no resíduo, como a caulinita e a mica e muito pouco relacionados a reações de redução do ferro. Foi evidenciado que um teor de apenas $1 \%$ de ferro no caulim poderia provocar efeitos de "inchamentos" após queima à $1500{ }^{\circ} \mathrm{C}$, com o subseqüente decréscimo da densidade [18, 24]. Entretanto, estudos evidenciaram que em composições com grande quantidade de alumina há a diluição do teor total de ferro e sua dissolução na alumina em altas temperaturas, o que diminui o efeito de sua redução na geração de gases, não se observando mais o decréscimo da densidade após queima a $1500{ }^{\circ} \mathrm{C}$ [23]. Comportamento semelhante foi observado nesse trabalho e em outros trabalhos, nos quais as composições com maiores teores de alumina apresentaram as maiores densidades aparentes e retrações de queima [28]. Entretanto, a menor intensidade da "superqueima" e "inchamento" nas composições com elevados teores de alumina também está associada ao fato da maior quantidade de alumina propiciar uma redução na quantidade total de fase líquida durante a queima. O maior teor de alumina também favorecerá a obtenção de fase líquida menos viscosa, o que facilitará a difusão dos íons e o crescimento dos cristais de mulita, propiciando um maior consumo de fase líquida durante a sinterização. Uma menor quantidade de fase líquida (e menos viscosa) "aprisionará" com menor intensidade os gases formados, permitindo que escapem de forma mais acentuada.

A Fig. 5 apresenta o módulo de ruptura à flexão das composições estudadas. De forma geral há um aumento do módulo com a quantidade de alumina utilizada nas composições; entretanto, essa relação é dependente da temperatura de queima. Por exemplo, após queima a $1500{ }^{\circ} \mathrm{C} \mathrm{a}$ composição A54 foi a que apresentou o maior módulo, enquanto que após queima a $1600{ }^{\circ} \mathrm{C}$, as composições A58 e A62 apresentaram as maiores resistências. O comportamento do módulo não é diretamente proporcional ao aumento da temperatura, possivelmente associado aos fenômenos de "superqueima" e "inchamento".

No presente trabalho não se observaram aumentos claros ou expressivos no módulo de ruptura das composições com excesso de sílica com o aumento da temperatura de queima, o que pode está associado à grande quantidade de fase líquida que se desenvolve durante a queima, ressaltando os efeitos da "superqueima" sobre as propriedades mecânicas do material. Entretanto, nas composições com maiores teores de alumina, como A54, A58 e A62, observa-se um aumento do módulo de ruptura com o aumento da temperatura de queima até a temperatura de $1550{ }^{\circ} \mathrm{C}$, o que possivelmente está associado à redução da quantidade de fase vítrea e aumento no teor de mulita dessas composições. Entretanto após queima a 1600 ${ }^{\circ} \mathrm{C}$ observa-se um decréscimo do módulo nas composições A54 e A58 e uma "estabilização" do módulo na composição 
A62, o que pode está associado à formação de uma grande quantidade de fase líquida após queima em temperatura superior à do eutético do sistema sílica-alumina, que associada à fase líquida provocada pela presença de elevado teor de fundentes, ressaltou os efeitos da "superqueima".

$\mathrm{O}$ aumento da resistência nas composições com maiores teores de alumina está, possivelmente, associado à redução na quantidade de fase vítrea no produto final, em virtude da reação entre a alumina e a fase líquida formada durante a queima, com a subseqüente produção de mulita. Em formulações triaxiais (porcelanas) também se observa que a substituição total ou parcial do quartzo por alumina (porcelanas) aumenta a resistência mecânica desses materiais. A utilização da alumina reduz a diferença entre o coeficiente de expansão térmica das fases cristalinas e da matriz vítrea, reduzindo a possibilidade de desenvolvimento de trincas durante o processamento [21], o que, associado ao favorecimento na produção de mulita e a diminuição na quantidade de fase vítrea após queima, aumenta a resistência desses materiais. Foram observados aumentos na resistência de porcelanas e de corpos mulíticos (obtidos a partir da sinterização reativa entre caulim e alumina) com o aumento na quantidade de alumina [21, 23, 29]. Entretanto, esses aumentos só foram observados após utilização de elevadas quantidades de alumina, superiores a $40 \%$. Assim, os dados obtidos nesse trabalho estão em consonância com a tendência retratada na literatura, apesar dos valores inferiores de resistência obtidos, que estão provavelmente associados à presença de elevada quantidade de fundentes no sistema que favorecem o desenvolvimento de uma grande quantidade de fase vítrea e a "superqueima" dos materiais.

Comparativamente com trabalhos da literatura [2, 13] que buscaram a produção de corpos mulíticos e refratários a partir de resíduos industriais, utilizando elevadas quantidade de resíduos em suas formulações e que obtiveram módulos em torno de $75 \mathrm{MPa}$, observa-se que os valores obtidos nesse trabalho estão de acordo com os que vêm sendo obtidos com a utilização de matérias-primas alternativas. Nesse sentido, a observação de estudos $[2,12,13,28]$ buscando alternativas para a reciclagem de resíduos industriais, através da produção de materiais cerâmicos com maior valor agregado, evidencia a importância da pesquisa desenvolvida e a necessidade de uma busca contínua por soluções que minimizem o descarte de resíduos e desperdício dos recursos naturais, mas que estejam de acordo com as necessidades econômicas a fim de favorecer o desenvolvimento sustentável.

\section{CONCLUSÕES}

Este trabalho teve por objetivo analisar a viabilidade de obtenção de corpos mulíticos através da utilização do resíduo do beneficiamento do caulim. Com base nos resultados obtidos pode-se concluir que:

- é possível a produção de corpos mulíticos a partir do resíduo do beneficiamento do caulim, utilizando elevadas quantidade de resíduos nas formulações, superiores a $40 \%$;

- a temperatura de queima dos corpos mulíticos produzidos utilizando o resíduo do caulim deve ser escolhida de acordo com a composição utilizada, em virtude da possibilidade de "superqueima" do material por conseqüência da grande quantidade de fundentes no resíduo;

- a evolução microestrutural das composições estudadas evidencia que é possível obter corpos mulíticos sem quartzo ou alumina residuais, através da adequada combinação das matérias-primas;

- os corpos com maior teor de alumina apresentaram maior resistência mecânica à flexão, atingindo valores da ordem de $75 \mathrm{MPa}$.

\section{AGRADECIMENTOS}

Ao CNPq (471414/04-9) e à FAPESQ/MCT/CNPq (003/03 e 001/06) pelo apoio financeiro.

\section{REFERÊNCIAS}

[1] R. R. Menezes, G. A. Neves, H. C. Ferreira, Rev. Bras. Eng. Agríc. Amb. 6, 2 (2002) 303.

[2] D. U. Tulyaganov, S. M. H. Olhero, M. J. Ribeiro, J. M. F. Ferreira, J. A. Labrincha, J. Mater. Synth. Process. 10, 6 (2002) 311 .

[3] F. Andreola, L. Barbieri, A. Corradi, I. Lancellotti, T. Manfredini, J. Eur. Ceram. Soc. 22 (2002) 1457.

[4] M. C. Zanetti, S. Fiore, Waste Manag. Res. 21 (2003) 235.

[5] L. P. F. Souza, H. S. Mansur, J. Mater. Process. Tech. 145 (2004) 14.

[6] F. Raupp-Pereira, O. Hotza, A. M. Segadães, J. A. Labrincha, Ceram. Int. 32, 2 (2006) 173.

[7] E. Ozel, S. Turan, S. Çoruh, O. N. Ergun, Waste Manag. Res. 24 (2006) 125.

[8] M. I. Sánchez de Rojas, F. Marin, J. Rivera, M. Frías, J. Am. Ceram. Soc. 89, 12 (2006) 3701.

[9] L. F. A. Campos, R. R. Menezes, D. Lisboa, L. N. L. Santana, G. A. Neves, H. C. Ferreira, Cerâmica 53, 328 (2007)

[10] R. R. Almeida, Dissertação de Mestrado, M. Sc. Universidade Federal de Campina Grande, Campina Grande, Paraíba, Brasil (2006).

[11] R. R. Menezes, M. I. Brasileiro, L. N. L. Santana, G. A. Neves, H. L. Lira, H. C. Ferreira, Waste Manage. Res., aceito.

[12] M. F. Souza, J. Yamamoto, Cerâmica 45, 291 (1999) 1. [13] T. Basegio, C. Haas, A. Pokorny, A. M. Bernardes, C. P. Bergmann, J. Hazardous Mater. B 137 (2006) 1156.

[14] S. R. Bragança, J. Vicenzi, K. Guerino, C. P. Bergmann, Waste Manage. Res. 24 (2006) 60.

[15] M. I. Brasileiro, D. H. S. Oliveira, H. L. Lira, L. N. L. Santana, G. A. Neves, A. P. Morais, J. M. Sasaki, Mater. Sci. Forum 530-531 (2006) 625.

[16] P. M. Souto, R. R. Menezes, R. H. G. A. Kiminami, Am. Ceram. Soc. Bull. 86, 1 (2007) 9201.

[17] R. R. Menezes, R. R. de Almeida, L. N. L. Santana, G. A. Neves, H. L. Lira, H. C. Ferreira, Cerâmica 53, 326 (2007) 192. 
[18] C. Y. Chen, W. H. Tuan, Ceram. Int. 27 (2001) 795. [19] Y. Iqbal, W. E. Lee, J. Am. Ceram. Soc. 83, 12 (2000) 3121.

[20] W. E. Lee, Y. Iqbal, J. Eur. Ceram. Soc. 21 (2001) 2583.

[21] Y. Iqbal, W. E. Lee, J. Am. Ceram. Soc. 82, 12 (1999) 3584.

[22] E. Bernardo, P. Colombo, E. Pippel, J. Woltersdorf, J. Am. Ceram. Soc. 89, 5 (2006) 1577.

[23] C. Y. Chen, G. S. Lan, W. H. Tuan, J. Eur. Ceram. Soc. 20 (2000) 2519.
[24] C. Y. Chen, G. S. Lan, W. H. Tuan, Ceram. Int. 26 (2000) 715 .

[25] E. Medvedovski, Ceram. Int. 32 (2006) 369.

[26] T. Tarvornpanich, G. P. Souza; W. E. Lee, J. Am. Ceram. Soc. 88, 5 (2005) 1302.

[27] G. P. Souza, P. F. Messer, W. E. Lee, J. Am. Ceram. Soc. 89, 6 (2006) 1993.

[28] H. S. Tripathi, G. Banerjee, J. Eur. Ceram. Soc. 18 (1998) 2081.

[29] A. L. Chinelato, D. P. F. de Souza, Cerâmica 50 (2004) 172.

(Rec. 09/05/2007, Ac. 15/06/2007) 